\title{
Karakteristik Temperatur Udara Terhadap Kenyamanan Termal Di Masjid Agung Luwuk Banggai
}

\author{
* Andi Alauddin ${ }^{1}$, Tayeb Mustamin ${ }^{2}$ \\ ${ }^{1}$ Jurusan Arsitektur, Fakultas Teknik, Universitas Tompotika Luwuk Banggai \\ ${ }^{2}$ Jurusan Arsitektur, Fakultas Teknik, Universitas Khairun Ternate \\ Alamat Email: andialauddinlabaso78@gmail.com \\ *Alamat korespondensi, Masuk: 23 Jul. 2019, Direvisi: 30 Jul. 2019, Diterima: 31 Jul. 2019
}

\begin{abstract}
ABSTRAK: Kenyamanan bangunan salah satunya dapat ditinjau dari perpindahan termal yang terjadi dalam bangunan tersebut. Masjid Agung An-Nur merupakan masjid yang menggunakan ventilasi alami dimana kondisi ruangan tersebut dipengaruhi secara langsung kondisi di luar ruangan pada pagi, siang dan malam. Penelitian ini bertujuan untuk menggambarkan karakteristik data temperatur udara di dalam bangunan. Pengolahan dan penyusunan data mengikuti standar panduan dari IDMP (International Daylight Measurement Programme). Data dikelompokkan dalam bentuk; data harian, dan mingguan selama 4 minggu setiap pelaksanaan Shalat Jumat, berdasarkan interval waktu setiap 30 menit. Hasil akhir disajikan dalam bentuk tabel dalam urutan: nilai rata-rata, standar deviasi, jumlah data, nilai maksimum, dan nilai minimum. Bentuk lainnya diperlihatkan dalam grafik/gambar fluktuasi yang menunjukkan nilai rata-rata, standar deviasi, nilai maksimum, dan nilai minimum, dilengkapi garis persamaan polynomial dari nilai rata-rata dan nilai koefisien korelasi data dari persamaan yang dihasilkan (R). Hasil penelitian menunjukkan karakteristik temperatur udara interior Masjid pada bulan Juni 2019 dengan nilai temperatur udara maksimum terjadi pada Jumat keempat dan minimum terendah pada Jumat ketiga. Hasil analisis berikutnya menunjukkan tingkat kesesuaian data dengan zona kenyamanan termal berdasarkan SNI (Standar Nasional Indonesia) setiap minggu.
\end{abstract}

Kata Kunci: Temperatur udara, Kenyamanan termal, Masjid

\begin{abstract}
One of the building comforts can be viewed from the thermal displacement that occurs in the building. Agung An-Nur Mosque is a mosque that uses natural ventilation where the condition of the room is directly affected by the conditions outside the morning, afternoon and night. This study aims to describe the characteristics of air temperature data outside the building. Processing and compilation of data follow the guidelines of the IDMP (International Daylight Measurement Program) standards. Data are grouped in the form of daily, and weekly for 4 weeks every Friday prayer, based on time intervals every 30 minutes. The final results are presented in table form in order: average value, standard deviation, number of data, maximum value, and minimum value. Other forms are shown in graphs/fluctuations that show average values, standard deviations, maximum values, and minimum values, equipped with polynomial equation lines of the average value and data correlation coefficient values of the resulting equation $(R)$. The results showed the temperature characteristics of the outside air in June 2019 with the highest maximum air temperature values occurring on the fourth and minimum Friday lowest on the third Friday. The results of the next analysis show the level of suitability of the data with the thermal comfort zone based on INS (Indonesian National Standard) every week.
\end{abstract}

Keywods: Air temperature, Thermal comfort, Mosque

\section{PENDAHULUAN}

Masjid adalah tempat melaksanakan berbagai kegiatan keagamaan bagi umat Islam. Kenyamanan dalam melakukan kegiatan di dalam ruangan merupakan salah satu faktor penting untuk menunjang aktivitas. Beberapa aspek kenyamanan di dalam ruangan, yaitu aspek pencahayaan, kebisingan kecepatan aliran udara, dan aspek termal.

Menurut Satwiko [1], bahwa Indonesia, meskipun kita merasa nyaman secara termal, namun tidak dapat dipungkiri bahwa ventilasi alami sulit diusahakan di iklim tropis yang lembap ini. 
Masjid Agung An-Nur Luwuk menggunakan bukaan ventilasi alami yang sangat sulit dilakukan di dalam iklim tropis. Maka dari itu akan dilakukan analis karakteristik temperatur udara dengan nilai temperatur udara maksimum tertinggi dan nilai minimum terendah pada setiap hari Jumat sewaktu pelaksanaan Shalat Jumat.

Masjid Agung An-Nur Luwuk memiliki sebuah bangunan masjid yang terletak di tengahtengah lokasi dan di luar site merupakan bangunan yang lebih rendah di sisi kiri dan kanan, Gambar 1.

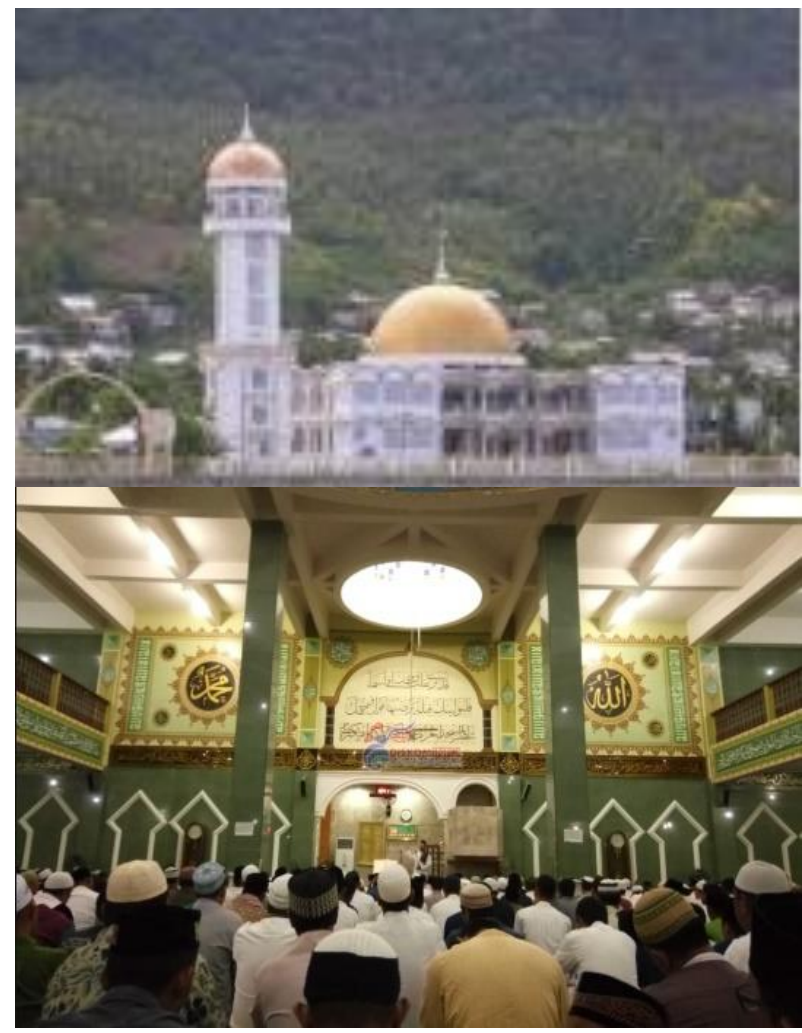

Gambar 1. Foto eksterior dan interior Masjid Agung An-Nur Luwuk

Bangunan masjid memiliki ketinggian lantai \pm 1-meter dari permukaan tanah. Desain arsitektur menggunakan tata udara alami di sekeliling bangunan. Infiltrasi udara dengan sistem ventilasi alami dapat digunakan untuk meningkatkan kenyamanan termal pada ruang-ruang dalam bangunan [2-5].

Penggunaan ventilasi alami pada bangunan masjid mengakibatkan kondisi iklim luar memberi pengaruh secara langsung terhadap ruangan di dalam masjid seperti perubahan angin, paparan sinar matahari, suhu udara, dan kelembapan. Oleh karena itu perlu adanya analisa terhadap perubahanperubahan tersebut, termasuk perpindahan termal pada ruang interior ruangan masjid.
Penelitian terbaru menyimpulkan bahwa ruangan pada rumah yang berada di iklim tropis panas dan lembap mengalami panas di siang hari, temperatur ruang dapat mencapai $35{ }^{\circ} \mathrm{C}$ [6]. Menurut penelitian sebelumnya [7], bahwa, pada suhu $27{ }^{\circ} \mathrm{C}-32{ }^{\circ} \mathrm{C}$ sebagian besar penghuni di dalam ruangan masih merasa nyaman dengan kondisi kecepatan aliran udara $1 \mathrm{~m} / \mathrm{s}$. Penelitian terbaru menemukan bahwa siswa-siswa Sekolah Dasar (SD) dan Sekolah Menengah Pertama (SMP) masih merasakan nyaman di dalam ruang kelas saat temperatur udara antara $28,5-32,3^{\circ} \mathrm{C}[8,9]$.

ASHRAE [10], Keenam faktor harus diatur ketika menentukan kondisi untuk kenyamanan termal yang dapat diterima: a) tingkat metabolisme; b) isolasi pakaian; c) temperatur udara; d) suhu radiasi; e) kecepatan udara; f) kelembapan udara.

Kenyamanan termal, seperti yang didefinisikan oleh Internasional Standard Organization, adalah hubungan yang kompleks antara temperatur udara, kelembapan udara, dan kecepatan aliran udara, ditambah lagi dengan jenis pakaian dan aktivitas serta tingkat metabolisme penghuni yang menghadirkan ungkapan perasaan kepuasan terhadap kondisi udara di dalam suatu lingkungan. Kondisi kenyamanan juga diartikan sebagai kenetralan termal, yang berarti bahwa seseorang merasa tidak terlalu dingin atau panas [11].

Menurut Nugroho et al. [12], kenyamanan termal dapat didefinisikan sebagai suatu kondisi pikiran yang mengekspresikan kepuasan terhadap lingkungan termal.

Mannan [2], untuk menciptakan kenyamanan termal, diketahui ada empat faktor yang mempengaruhi kemampuan tubuh manusia menyalurkan kalor, yaitu: a) temperatur/suhu $\left({ }^{\circ} \mathrm{C}\right)$; b) kelembapan relatif (\%); d) kecepatan udara (m/det.); dan e) mean radiant temperature (MRT).

\section{Temperatur Udara}

Definisi temperatur adalah suatu ukuran energi kinetik rata-rata dari suatu molekul. Jika temperatur tinggi maka energi kinetik rata-rata pun akan besar. Pengertian temperatur udara adalah panas atau dinginnya suatu udara.

Perubahan temperatur udara disebabkan oleh adanya kombinasi kerja antara udara, perbedaan kecepatan proses pendinginan \& pemanasan suatu daerah dan jumlah kadar air di permukaan bumi.

\section{Kenyamanan Termal}

Menentukan temperatur dasar atau temperatur referensi, penelitian ini mengacu pada standar kenyamanan termal Indonesia SNI T-14-1993-03 [13] ada tiga: a) sejuk nyaman, $20,5^{\circ} \mathrm{C}-22,8^{\circ} \mathrm{C}$, kelembapan relatif $50 \%-80 \%$; b) nyaman optimal 
$22,8{ }^{\circ} \mathrm{C}-25,8{ }^{\circ} \mathrm{C}$, kelembapan relatif $70 \%-80 \%$; c) hampir nyaman $25,8{ }^{\circ} \mathrm{C}-27,1^{\circ} \mathrm{C}$, kelembapan relatif $60 \%-70 \%$. Berdasarkan ketiga standar di atas, terlihat temperatur paling rendah adalah 20,5 ${ }^{\circ} \mathrm{C}$ dan yang tertinggi $27,1^{\circ} \mathrm{C}$.

Baharuddin [14,15], kenyamanan yang paling dominan pengaruhnya terhadap kenyamanan fisik manusia yang berada dalam bangunan adalah kenyamanan termal, meliputi: temperatur udara, kelembapan udara dan kecepatan aliran udara. Satwiko [1], berpendapat kenyamanan termal daerah tropis lembap dapat dicapai dengan batasbatas $24^{\circ} \mathrm{C}<\mathrm{T}<26^{\circ} \mathrm{C}, 40 \%<\mathrm{RH}<60 \%, 0,6<\mathrm{V}<1,5$ $\mathrm{m} /$ det, kegiatan santai, pakaian ringan dan selapis.

Kelembapan relatif adalah parameter kenyamanan termal penting lainnya. Tingkat kelembapan relatif yang tinggi akan meningkatkan tingkat ketidaknyamanan di ruang yang te rlalu panas. Menurut Ismail [16], dalam kondisi panas dan lembap di Malaysia, aliran udara alami akan meningkatkan proses penguapan untuk mencapai tingkat kenyamanan tertentu. ASHRAE menunjukkan bahwa kelembapan relatif udara antara $40 \%$ dan $60 \%$ dianggap sehat dan nyaman di lingkungan yang dikendalikan kenyamanannya. Berdasarkan Ibrahim [17], peningkatan kecepatan udara akan mengurangi efek kelembapan tinggi dan meningkatkan kapasitas penguapan dari tubuh manusia. Menurut Seeley [18], dalam iklim panas dan lembap, kelembapan relatif berlaku di dataran rendah ekuatorial di daerah tropis dekat permukaan laut. Dengan demikian, bangunan harus dirancang untuk meminimalkan efek kelembapan pada kondisi iklim ini.

Berdasarkan uraian di atas, terlihat telah banyak penelitian bahkan teori tentang kenyamanan termal di dalam ruangan, belum banyak penelitian yang berkonsentrasi pada kenyamanan di bangunan rumah ibadah seperti Masjid. Oleh karena itu penelitian untuk mengetahui karakteristik temperatur udara di luar bangunan, dengan model pengolahan data mengikuti standar Panduan dari IDMP (International Daylight Measurement Programme) pada masjid Agung An-Nur di Luwuk.

\section{METODE DAN ALAT PENELITIAN}

Metode penelitian adalah eksperimental dan pengukuran. Pengumpulan data lapangan dengan melakukan pengukuran dan observasi pada Masjid Agung An-Nur Luwuk. Pengolahan data menggunakan analisis kuantitatif dengan sumber data diperoleh dari alat Hobo Data Logger yang dipasang pada lima buah titik yang di tentukan di dalam Masjid, Gambar 2.

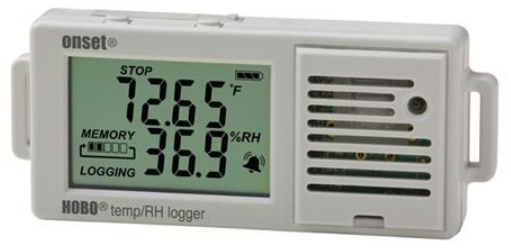

Gambar 2. Alat ukur Hobo Data Logger

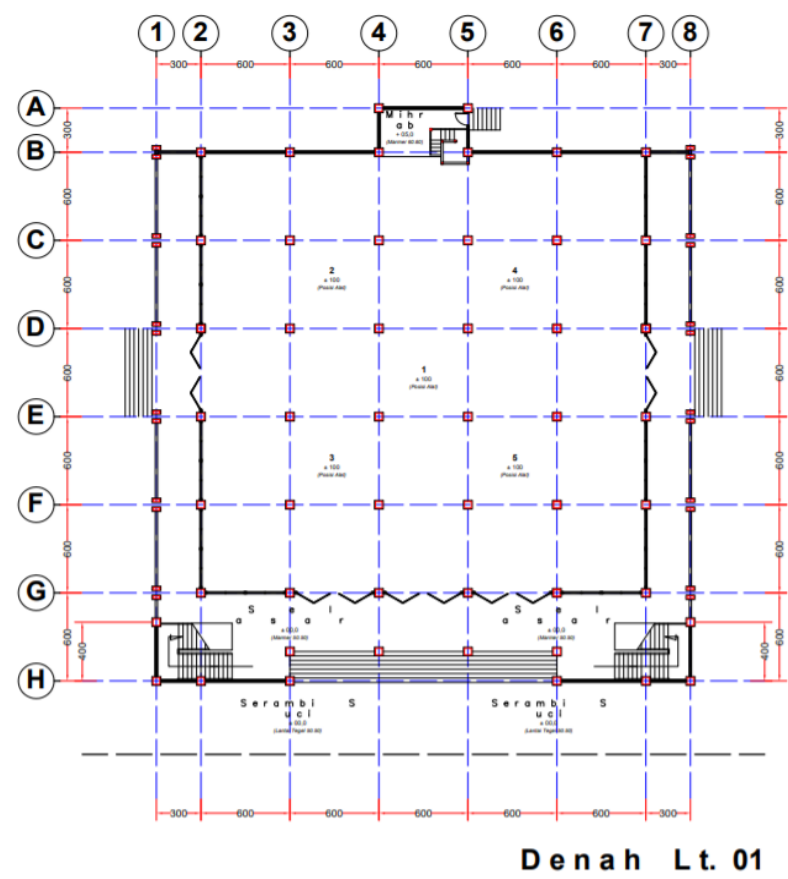

Gambar 3. Titik peletakan alat ukur

Perangkat tersebut diletakkan di dalam ruangan sebanyak 5 titik, pada posisi kiri, kanan dan tengah ruangan kemudian dirata-ratakan, dengan ketinggian alat $100 \mathrm{~cm}$ dari lantai, Gambar 3.

Data tersusun diawali dengan data Tanggal dan Waktu, Nomor Data, disusul dengan komponen data iklim yang diukur. Komponen data iklim tersebut adalah hanya Temperatur Udara $\left({ }^{\circ} \mathrm{C}\right)$, variabel lain tidak termasuk dalam kajian ini.

Pengolahan dan penyajian data disajikan dalam bentuk data harian yang dilakukan selama empat minggu. Selanjutnya, data harian disusun berdasarkan: interval waktu setiap 30 menit.

Data disajikan dalam bentuk tabel dalam urutan: nilai rata-rata, standar deviasi, jumlah data, nilai maksimum, dan nilai minimum. Bentuk lainnya diperlihatkan dalam grafik /gambar fluktuasi yang menunjukkan nilai rata-rata, standar deviasi, nilai maksimum, dan nilai minimum, dilengkapi garis persamaan polinomial dari nilai rata-rata dan nilai koefisien korelasi data dan persamaan yang dihasilkan (R2), Rahim [19], Martosenjoyo et al. [20]. 


\section{HASIL DAN PEMBAHASAN}

Jumlah data terekam terdiri dari: 4 Jumat dalam sebulan, pada bulan Juni 2019. Total hari pengukuran sebanyak 4 hari dengan total 240 data.

Pada tabel 1 diperlihatkan data temperatur tertinggi yang terjadi pada tanggal 28 Juni 2019 $\left(>32.75^{\circ} \mathrm{C}\right)$. Kondisi tersebut jauh melebihi zona nyaman dalam ruangan. Pada pukul 12.01 suhu sudah menunjukkan $32.39{ }^{\circ} \mathrm{C}$ sampai selesainya pelaksanaan Shalat Jumat suhu mencapai $32.75^{\circ} \mathrm{C}$.

Tabel 1. Karakteristik Data Temperatur Tertinggi

\begin{tabular}{cccccc}
\hline 28 Juni 2019 & \multicolumn{5}{c}{ TEMPERATUR UDARA $\left({ }^{\circ} \mathrm{C}\right)$} \\
\hline WAKTU & JUMAT 4 & STDV & DATA & MAX & MIN \\
\hline $12.01-12.30$ & 32.39 & 0.04 & 30 & 32.48 & 32.32 \\
$12.31-13.00$ & 32.75 & 0.16 & 30 & 33.03 & 33.03 \\
\hline
\end{tabular}

Gambar 4 merupakan grafik karakteristik temperatur udara tertinggi dan grafik data temperatur selama keempat Jumat bulan Juni pada tahun 2019. Pada jam 12.00 temperatur sudah menunjukkan angka $32.3{ }^{\circ} \mathrm{C}$ sampai pada jam 13.00 angkanya terus naik mencapai suhu $33.70{ }^{\circ} \mathrm{C}$.

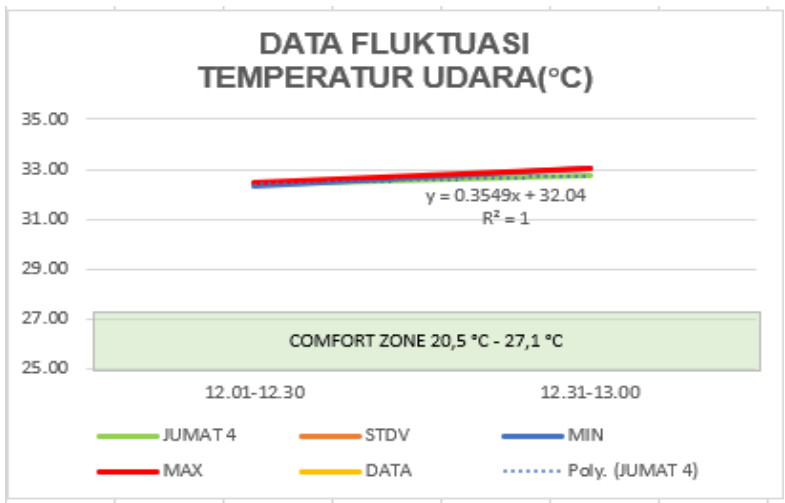

Gambar 4. Data Temperatur 28 Juli 2019

Pada tabel 2 diperlihatkan data temperatur terendah yang terjadi pada tanggal 21 Juni 2019 $\left(>30.40{ }^{\circ} \mathrm{C}\right)$. Kondisi tersebut masih melebihi zona nyaman untuk dalam ruangan.

Tabel 2. Karakteristik Data Temperatur Terendah

\begin{tabular}{cccccc}
\hline 21 Juni 2019 & \multicolumn{5}{c}{ TEMPERATUR UDARA $\left({ }^{\circ} \mathrm{C}\right)$} \\
\hline WAKTU & JUMAT 4 & STDV & DATA & MAX & MIN \\
\hline $12.01-12.30$ & 30.40 & 0.09 & 30 & 30.50 & 30.22 \\
$12.31-13.00$ & 30.57 & 0.02 & 30 & 30.60 & 30.60 \\
\hline
\end{tabular}

Gambar 5 merupakan grafik karakteristik temperatur udara terendah selama empat kali pengukuran pada bulan Juni tahun 2019. Pukul
12.00 temperatur sudah menunjukkan angka 30.21 ${ }^{\circ} \mathrm{C}$ sampai pada jam 13.00 angkanya terus naik mencapai suhu $30.59^{\circ} \mathrm{C}$.

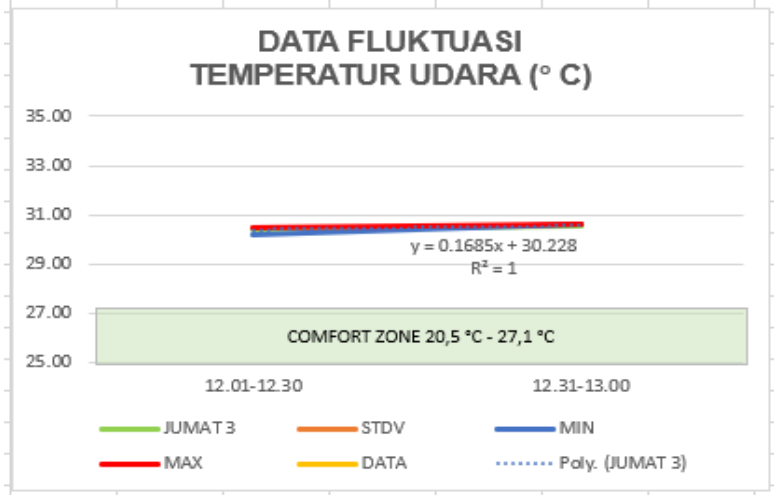

Gambar 5. Data Temperatur 21 Juni 2019

Selama empat Jumat data temperatur sangat beragam mulai dari $30{ }^{\circ} \mathrm{C}$ sampai $32{ }^{\circ} \mathrm{C}$. Jumat pertama suhu mencapai rata-rata $31.39{ }^{\circ} \mathrm{C}$ selanjut suhu terus naik pada Jumat kedua mencapai ratarata $32.47{ }^{\circ} \mathrm{C}$.

Tabel 3. Karakteristik Data Temperatur Selama Empat Jumat

\begin{tabular}{ccccc}
\hline \multicolumn{5}{c}{ TEMPERATUR UDARA $\left({ }^{\circ} \mathrm{C}\right)$} \\
\hline JUMAT 1 & STDV & DATA & MAX & MIN \\
\hline 31.39 & 0.16 & 30 & 31.58 & 31.12 \\
31.66 & 0.12 & 30 & 31.83 & 31.83 \\
\hline JUMAT 2 & STDV & DATA & MAX & MIN \\
\hline 32.12 & 0.34 & 30 & 32.40 & 31.41 \\
32.47 & 0.07 & 30 & 33.66 & 32.66 \\
\hline JUMAT 3 & STDV & DATA & MAX & MIN \\
\hline 30.40 & 0.09 & 30 & 30.50 & 30.40 \\
30.50 & 0.02 & 30 & 30.60 & 33.60 \\
\hline JUMAT 4 & STDV & DATA & MAX & MIN \\
\hline 32.30 & 0.04 & 30.00 & 32.48 & 32.30 \\
32.70 & 0.16 & 30.00 & 33.03 & 33.00 \\
\hline
\end{tabular}

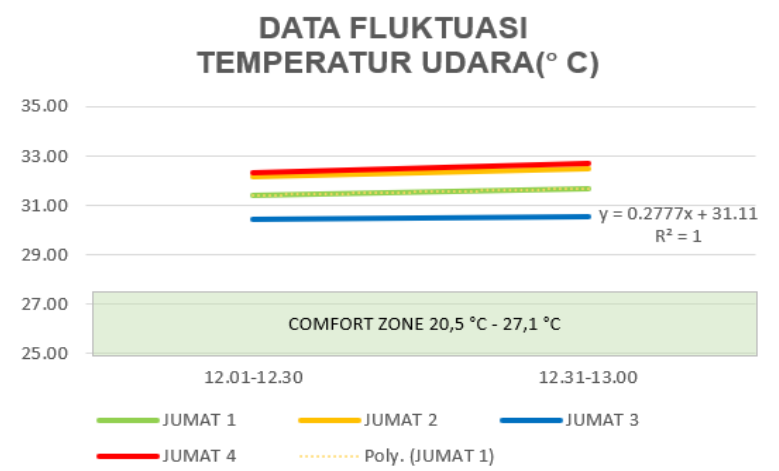

Gambar 6. Fluktuasi Data Temperatur Selama Empat Jumat Bulan Juni 2019 
Berdasarkan hasil pengukuran di dalam Masjid dari 12.02 hingga 13.30 WITA setiap Jumat selama bulan Juni 2019 yaitu tanggal 7, 14, 21 dan 28. Temperatur udara menunjukkan nilai yang tinggi antara $30,2^{\circ} \mathrm{C}-33,7^{\circ} \mathrm{C}$. Nilai ini sangat tinggi jika dibandingkan dengan standar nasional Indonesia SNI [13]. Jika dibandingkan dengan penelitian yang dilakukan oleh beberapa penelitian sebelumnya [7-9,14], maka penelitian ini menguatkan penemuan sebelumnya bahwa temperatur ruang-ruang yang menggunakan ventilasi alami mengalami panas terutama di siang hari. Pada saat Shalat Jumat, temperatur udara dalam ruang Masjid meningkat disebabkan oleh panas yang dikeluarkan oleh tubuh jamaah, dan tidak berfungsinya sistem ventilasi alami secara efektif. Untuk mengatasi panas dalam ruangan, biasa dinyalakan kipas angin. Solusi ini dapat diambil karena akan meningkatkan distribusi aliran udara dalam ruangan $[4,5,21]$. Walaupun solusi ini cukup mengurangi panas yang dirasakan oleh jamaah, namun tidak dapat menurunkan temperatur udara ruangan secara efektif.

\section{KESIMPULAN DAN SARAN}

Data yang diperoleh dari pengukuran komponen iklim di Masjid Agung An-Nur Luwuk telah diolah dan dianalisis yang menggambarkan karakteristik data temperatur udara di dalam bangunan. Data disusun berdasarkan panduan dari IDMP (International Daylight Measurement Program) memberikan informasi data yang akurat untuk berbagai analisis lanjutan dalam kaitannya dengan kenyamanan termal dalam bangunan. Dengan penyajian menggunakan program Microsoft Excel tabel data setiap Jam. Selanjutnya, data tersebut disusun berdasarkan: interval waktu setiap 30 menit.

Bentuk lainnya diperlihatkan dalam grafik/gambar fluktuasi yang menunjukkan nilai rata-rata, standar deviasi, nilai maksimum, dan nilai minimum, dilengkapi garis persamaan polynomial dari nilai rata-rata dan nilai koefisien korelasi data dari persamaan yang dihasilkan (R2).

Dapat disimpulkan bahwa selama empat kali pengukuran di hari Jumat saat dilakukan Shalat berjamaah antara jam 12.01 - 13.30 WITA, kondisi termal tercatat pada variabel temperatur udara diatas standar kenyamanan termal yaitu berkisar antara $30,2{ }^{\circ} \mathrm{C}-33,7^{\circ} \mathrm{C}$.

Disarankan untuk melakukan penelitian sejenis dengan membandingkan beberapa Masjid. Titik alat ukur yang lebih banyak antara ruang interior dan ruang eksterior, serta dilakukan pada saat yang bersamaan. Penggunaan metode simulasi sangat dianjurkan untuk analisis sistem ventilasi Masjid.

\section{DAFTAR PUSTAKA}

[1] Satwiko P (2009) Fisika Bangunan. Yogyakarta: Penerbit ANDI. ISBN: 978-979-29-0734-6.

[2] Mannan A (2007) Faktor Kenyamanan Dalam Perancangan Bangunan (Kenyamanan Suhu - Termal Pada Bangunan). Jurnal Ichsan Gorontalo Vol. 2, No. 1: hal. 466-473.

[3] Sugini S (2004) Pemaknaan Istilah-Istilah Kualitas Kenyamanan Thermal Ruang Dalam Kaitan Dengan Variabel Iklim Ruang. Jurnal Logika Vol. 1, No. 2.

[4] Latif S, Hamzah B, Ihsan (2016) Pengaliran udara untuk kenyamanan termal ruang kelas dengan metode simulasi computational fluid dynamics. Sinektika Vol. 14, No. 2: hal. 209-216.

[5] Latif S, Hamzah B, Rahim R, et al. (2019) Computational Study of the Heat Ventilation on The Attics of Buginese Houses. 1st International Conference on Science and Technology; 2-3 May 2019; Makassar, Indonesia. hal. 8-13.

[6] Latif S, Idrus I, Ahmad A (2019) Kenyamanan Termal pada Rumah Kos (Studi Kasus Pondok Istiqomah di Makassar). Jurnal LINEARS Vol. 2, No. 1: hal. 1-7.

[7] Baharuddin H, Muhammad TI, Asniawaty K (2015) Pengaruh Kecepatan Aliran Udara Terhadap Tingkat Kenyamanan Termal di Ruang Kuliah.

[8] Latif S, Rahim R, Hamzah B (2016) Analisis Kenyamanan Termal Siswa di Dalam Ruang Kelas - Studi Kasus SD Inpres Tamalanrea IV Makassar. Simposium Nasional Rekayasa Aplikasi Perancangan dan Industri (RAPI XV); 7 December; Hotel Alila, Surakarta. hal. 466-473.

[9] Hamzah B, Gou Z, Mulyadi R, et al. (2018) Thermal comfort analyses of secondary school students in the tropics. Buildings Vol. 8, No. 4: hal. 56-75.

[10] ASHRAE - (2017) Standard 55-2017 Thermal Environmental Conditions for Human Occupancy. Ashrae: Atlanta, GA, USA

[11] ISO-7730 (1994) Moderate Thermal Environments -- Determination of The PMV and PPD Indices and Specification of The Conditions for Thermal Comfort. Switzeland: International Organization for Standardization.

[12] Nugroho AM, Ahmad MH, Ossen DR (2007) A preliminary study of thermal comfort in Malaysia' s single storey terraced houses. Journal of Asian Architecture Building Engineering Vol. 6, No. 1: hal. 175-182.

[13] LPMB-PU S (1993) Standar Tata Cara Perencanaan Teknis Konservasi energi pada Bangunan Gedung (SK SNI T14-1993-03). Bandung: Yayasan Lembaga Penelitian Masalah Bangunan. 
[14] Hamzah B, Mulyadi R, Amin S (2017) Thermal Comfort Analyses of Elementary School Students in the Tropical Region. In: Schnabel MA, editor. 51st International Conference of the Architectural Science Association (ANZAScA); 29 November - 2 December 2017; Wellington New Zealand. Department of Architecture, Victoria University of Wellington. hal. 723-732.

[15] Hamzah B, Rahim R, Ishak T, et al. (2017) Kinerja sistem ventilasi alami ruang kuliah. Jurnal Lingkungan Binaan Indonesia Vol. 10: hal. 51-57.

[16] Ismail AM (1996) Wind-driven natural ventilation in high-rise office buildings with special reference to the hothumid climate of Malaysia: Cardiff University.

[17] Ibrahim SH (2004) Thermal comfort in modern low-income housing in Malaysia: University of Leeds.

[18] Seeley IH (1986) Building technology: Macmillan International Higher Education. ISBN: 1349092231.

[19] Rahim R (2009) Teori dan aplikasi distribusi luminansi langit di Indonesia: Jurusan Arsitektur Fakultas Teknik. ISBN: 9791546932.

[20] Martosenjoyo T, Baharuddin YO, Dahri Kuddu RH (2016) Pengukuran dan Pengolahan Data Komponen Iklim di Makassar. Prosiding Temu Ilmiah IPLBI; Malang.

[21] Lippsmeier G (1994) Tropenbau Building in the Tropics (Bangunan Tropis). Nasution S, translator. Jakarta: Penerbit Erlangga. 